\title{
NA CIUDAD PROPIA: LA REPRESENTACIÓN DEL ESPACIO URBANO EN LAS OBRAS SURREALISTAS DE REMEDIOS VARO Y EMMY HAESELE
}

ROCÍO SOLA JIMÉNEZ

Departament d'Humanitats. Universitat Pompeu Fabra rocio.sola@upf.edu

\begin{abstract}
Resumen: La sombra del Surrealismo es alargada, tanto, que se extiende más allá de la época de los manifiestos y más allá del Atlántico, donde evoluciona hacia lo que se ha venido denominando "Realismo mágico". No obstante, en esta evolución tanto temporal como de contenidos, los principios del automatismo y de las imágenes procedentes del mundo de lo mágico, de los sueños y de los estratos más profundos de la conciencia se encuentran en un marco del que poco se ha hablado hasta ahora: la ciudad. Más precisamente, la ciudad como espacio femenino. Otro de los aspectos que parecen haber quedado en el tintero en los estudios sobre el Surrealismo es lo que ocurre fuera de este México mágico. Aquí se muestra, a partir de la comparación de la bien conocida artista española Remedios Varo y de la total desconocida artista austriaca Emmy Haesele, una reflexión sobre hasta qué punto su arte estuvo influenciado por el círculo de artistas que las impulsaron así como por las ideas de "exilio" y "persecución", dándole a raíz de esto un mayor sentido a la percepción del espacio urbano que las rodeó y a la confección de una ciudad que les era totalmente propia.
\end{abstract}

Palabras clave: Surrealismo / Ciudad / Remedios Varo / Emmy Haesele / Espacios de identidad.

\section{A WHOLE CITY: DEPICTION OF THE URBAN AREA ON REMEDIOS VARO AND EMMY HAESELE SURREALIST WORK}

Abstract: Surrealism casts a long shadow, it goes beyond the time of writing manifestos and over and beyond the Atlantic Ocean -where it evolves into what has been called "Magic Realism". In the course of this years of artistic evolution, some principles of surrealism -like automatic writing and creating images out of the world of magic and dreams- hold the line on exploring the deepest layers of consciousness. In order to do so, another unexplored and not so much considered element showed up in some artists' works: the city. The city as a feminine space, more precisely. Another aspect that seems to be neglected in the studies of Surrealism is to take into consideration what happened in other places aside this magical Mexico. In this paper it would be discussed how Surrealism and its circles influenced both the well-known Spanish artist Remedios Varo and the lesser known Austrian artist Emmy Haesele. The ideas of "exile" and "persecution" also drawn the line on how these two artists perceived their own urban space in the time they lived, influencing in the creation of an artistic city of their own.

Key words: Surrealism / City / Remedios Varo / Emmy Haesele / Spaces of Identity.

El Surrealismo floreció en medio del terreno que abonaron movimientos de Vanguardia como Dadá, con la puesta en duda de lo racional a la hora de representar el mundo. Se abría camino así un movimiento que se alzaba en pos de lo extraordinario, de lo ritual, de la libertad, en el contexto de una Europa dolorida que se recomponía tras la gran sacudida de la I Guerra Mundial.
El ritmo que marcó el grupo del Cabaret Voltaire latía a contra compás de la máquina y funcionó como piedra angular para el Surrealismo a la hora de fundamentar su teoría sobre los objetos dentro de la composición artística: construir a partir de las nuevas posibilidades de expresión, crear objetos trascendentes y revolucionarios en el entramado social y artístico, reconsiderando

* Fecha de recepción: 15 de abril de 2018 / Fecha de aceptación: 25 de noviembre de 2018. 
aquello que se les ofrecía al alcance de sus manos.

Con el Surrealismo se comienza a trabajar en la confección de un nuevo cosmos que funciona mediante el mecanismo de la oposición. Para el artista surrealista, los objetos que nos rodean se hacen eco de las fuerzas espirituales del universo, permitiendo a su vez la evasión hacia otros horizontes que se expanden más allá de los meros límites corporales. ${ }^{1}$ Prevalece la idea de juego a la hora de considerar el significado de los mismos. Para los artistas surrealistas los objetos son comprendidos en primera instancia como "todo aquello que se opone al sujeto". De la relación entre el artista y el objeto consigue extraerse toda vinculación con la materia, con la forma, con la función, dando lugar a una constelación artística donde los significados se desdoblan y donde toda percepción y toda asociación son posibles.

Esta nebulosa de objetos, ordenados en un espacio que pertenece al mundo de lo imaginario, de los sueños y del inconsciente, se sobrepone a la percepción que los propios artistas tenían de su entorno, de la ciudad. Si bien dentro del movimiento surrealista no existió una teoría sólida referente a la ciudad, como tampoco existió un urbanismo surrealista, sí que se pueden extraer ideas aisladas que ayudan a configurar el gran cosmos de la ciudad percibida por los ojos de los artistas surrealistas. ${ }^{2}$ La ciudad como objeto surrealista y como elemento de deleite estético comparte a grandes rasgos algunos preceptos que más tarde abanderaría la Internacional Situacionista, como por ejemplo el concepto de "Deriva" o la idea de "Psicogeografía", que pueden rastrearse en grandes obras de la literatura surrealista como es el caso de Nadja (1928) o Los vasos comunicantes (1932) de André Breton.

La manera que los surrealistas tenían de transmitir y aplicar los principios de su mundo interior a los objetos que les rodeaban les hacía encontrar en componentes del cosmos las características de un cuerpo viviente, de modo que cualquier inte- racción con los mismos era capaz de causar transformaciones en el cuerpo de lo real. ${ }^{3}$ A partir de la experiencia del espacio, el artista-flaneur dibujaba, con su "Deriva" por las calles de la ciudad, el perfil del ente urbano de la misma manera en la que, mediante el enfrentamiento entre "yo" y "el otro", se dibujaba el umbral hacia todas las potenciales identidades y aproximaciones de aquello que observamos.

El teórico francés Michel Onfray ${ }^{4}$ reúne la imagen del flaneur baudelaireano junto con el concepto de "Deriva" situacionista cuando afirma que, precisamente, la experiencia de hacer avanzar el cuerpo por la ciudad supone desatar determinados mecanismos tanto estéticos como psicológicos que amenazan el concepto de individualidad. La masa de la ciudad, a la que Edgar Allan Poe también le dedicó un espacio en El hombre en la multitud (1840), convierte al individuo en un ser inadvertido que sólo será tenido en consideración y celebrado en el momento en que pone su existencia al servicio de la causa que lo supera y a la que todos rinden culto. ${ }^{5}$

Al amparo de las palabras de Onfray, es imposible no reflexionar acerca del rol que jugaron las mujeres dentro del movimiento surrealista. La mujer en el Surrealismo ha pasado a la historia como musa y acompañante, cuando verdaderamente jugó un rol importante dentro de la evolución del movimiento: fueron artistas, coleccionistas e incluso críticas de arte. Esta invisibilidad las pone en relación con la propia idea de ciudad, un elemento estético y pasivo, así como con la idea de disolución dentro en una masa que las arrastraba sin llegar a ser advertidas.

La ciudad de París fue personificada y fetichizada de forma recurrente por parte del movimiento Surrealista, cuyos orígenes se encuentran en la tradición literaria decimonónica. Un claro ejemplo de esto es Nadja, de André Breton, en cuyo personaje principal se cruzan no sólo las palabras "nadie" y "esperanza", 6 sino que también se cruzan las ideas de musa femenina y ciudad en un modelo

\footnotetext{
1 CIRLOT, Juan Eduardo. El mundo del objeto a la luz del surrealismo. Barcelona, Athropos, 1986, p. 95.

2 BARREIRO LEÓN, Bárbara. "Psicogeografía y ciudad: iconografía del urbanismo surrealista", en Ángulo Recto. Revista de estudios sobre la ciudad como espacio plural. 7, (1), 2015, pp. 5-12.

${ }^{3}$ CIRLOT, Juan Eduardo. 1986, p. 16.

4 ONFRAY, Michel. Política del rebelde. Barcelona, Anagrama, 2011.

${ }^{5}$ ONFRAY, Michel. 2011, p. 41.

${ }^{6}$ El propio Breton comienza su novela autobiográfica diciendo que el nombre de "Nadja" procede del comienzo de la palabra rusa "Esperanza", y que es sólo el principio, así como también coquetea con la palabra "Nadie" en español, dejando la novela abierta a la propia experiencia de búsqueda del personaje, de la esperanza, por una ciudad altamente estetizada y aderezada por el trasfondo de la locura, altamente apreciada por los artistas surrealistas.
} 
que nos lleva al siglo XIX, más concretamente a la novela Aurélia, o el Sueño y la Vida (1855), de Gérard de Nerval. Ambas son obras extremadamente visuales, sinestéticas y a modo de autobiografías, donde las vivencias de los autores afectan a la manera de entender el entorno por el que se mueven. Aurélia también aborda el problema de la locura, de lo meramente visionario, donde, en palabras de Carl Gustav Jung, el protagonista presencia la creación y la evolución de la vida en la tierra, en un descenso peligroso hacia una experiencia primigenia que sobrepasa el entendimiento humano, que deriva hacia los estratos más profundos del sueño y la locura, a los cuales es muy fácil sucumbir. ${ }^{7}$ En este sentido y tirando del hilo de André Breton nos encontramos con la primera obra, también literaria, del puño y letra de una de las artistas más emblemáticas del Surrealismo: Leonora Carrington con su escrito Memorias de Abajo (1943).

Leonora Carrington entró en el círculo de los surrealistas de la mano de Max Ernst en 1937 y fue considerada durante muchos años como una musa surrealista, cuando verdaderamente fue una de las promotoras del Surrealismo al otro lado del Atlántico a partir de los años 50. Presa de una terrible crisis psicológica que sufrió tras el arresto de Max Ernst en 1939, considerado enemigo del régimen de Vichy, Carrington puso rumbo a España, donde sería confinada en un sanatorio de Santander. Esta experiencia le hizo perder el sentido de la realidad y de la propia identidad en lo que posteriormente André Breton consideraría un ejemplo sublime de la ya romantizada histeria y locura femenina. Así pues, una década después y habiéndose exiliado ya Carrington en México, Breton la insta a escribir sus vivencias en el sanatorio, dando lugar a un texto mucho más crudo y psicológico que el que muestra en Nadja, novela que ya había sido elevada a los altares de literatura psicológica y que ha seguido ensombreciendo el relato de Carrington hasta nuevas relecturas ya en nuestros días.

En la comparativa de ambos textos podemos entrever un tránsito que va desde la ciudad abierta en Nadja hacia el espacio cerrado en Memorias de abajo, una transición que podría entenderse como un contraste entre el espacio público masculino y el entorno cerrado femenino. Pablo Aros Legrand observa que ya en el trazado inicial de las ciudades subyacía una idea que apelaba al sometimiento del cuerpo femenino, ${ }^{8}$ sometimiento que, en el mundo de la literatura y del arte hecho por mujeres, se elimina. La ciudad como símbolo, no obstante, seguía fuertemente marcada por el punto de vista de una hegemonía masculina. Es por esto por lo que muchas veces el propio lenguaje femenino habla de entornos cerrados, de protección, trazando un itinerario que transita de la ciudad al hogar, al refugio. Este itinerario está marcado muchas veces por referencias al paso del tiempo y a la memoria, a lo ritual, a lo femenino sagrado, dando lugar a un discurso en espiral, que lo abarca todo y que evidencia los abusos externos aplicados a la entidad corporal femenina. ${ }^{9}$

A partir del siglo XIX, y de manera más aguda desde los inicios del Surrealismo en adelante, la relación entre cuerpo y ciudad se vuelve un recurso poético bastante común. La escisión romántica de hombre y naturaleza acaba por aunarse en una moderna simbiosis entre arquitectura urbana y naturaleza. No obstante, esta asociación es un arma de doble filo, pues igual que mantiene viva la relación entre creación y entorno natural, la ciudad y la arquitectura se emancipan del control humano dando lugar a un contexto en el que todo es máquina y la vida huye por todas partes. ${ }^{10}$ Esta dualidad de naturaleza creadora y destructora también guarda paralelismos con la iconografía con la que venía representándose tradicionalmente a la mujer. La Femme Fatale y la Donna Angelicata pueblan los grandes temas de la cultura occidental, haciendo incluso aparición en los fundamentos del Psicoanálisis de la Escuela de Viena.

El psicoanálisis moderno también recoge estas dos dualidades cuando compara la imagen de la ciudad con el símbolo de la Madre en su doble aspecto de protectora y controladora. ${ }^{11}$ Dentro de esta ciudad, la casa se alza como el punto medio entre el macrocosmos de lo urbano y el microcos-

\footnotetext{
7 JUNG, Carl Gustav \& STEPHENSON, Craig E. On Psychological and Visionary Art. Notes from C. G. Jung on Nerval's Aurélia. Princeton, Princeton University Press, 2015.

8 AROS LEGAND, Pablo. "Cuerpo de mujer: la ciudad como constructo en el discurso poético femenino desde los años ochenta hasta la actualidad en Chile", en Ángulo Recto 9 (1), 2017, pp. 5-15. Madrid, Ediciones Complutense, p. 7.

${ }^{9}$ AROS LEGRAND, Pablo. 2017, p. 12.

10 LUQUín CALVO. Andrea. Remedios Varo: el espacio y el exilio. San Vicente del Raspeig, Centro de Estudios sobre la Mujer (Universidad de Alicante), 2008, p. 193.

11 CHEVAliER, Jean \& GHEERBRANT, Alain. Diccionario de los Símbolos. Barcelona, Herder, 1991.
} 
mos de lo personal, ${ }^{12}$ brindando una idea de refugio que igualmente puede tornarse en un elemento claustrofóbico y opresor, razón por la cual los artistas (y especialmente las mujeres artistas) han sentido cierta predilección por las ventanas. Leonora Carrington en Memorias de abajo, sirve como ejemplo para ilustrar la idea del abuso físico y psicológico ligado a la idea del espacio cerrado así como al cuerpo de la gran urbe.

Mientras Carrington padecía en Santander, se extendía por Europa el águila del fascismo, que no sólo disgregó la comunidad surrealista, sino que agregó una mayor connotación negativa a lo urbano y a la idea de "progreso". En este contexto, los mundos imaginarios creados por el Surrealismo, así como todo atisbo de fantasía, quedaron proscritos y condenados. No obstante, los artistas surrealistas no eran conscientes de que, dentro de su concepción de ciudad y de su relación con lo fantástico, también lo femenino como tal quedaba excluido, sufriendo ellas en este contexto una doble exclusión.

No será hasta la década de 1950, durante lo que Charlotte Moore denomina "Surrealismo tardío", ${ }^{13}$ cuando un grupo de artistas, mujeres, se dediquen a crear un arte que abandonó el terreno freudiano (donde la mujer o era castradora o era musa deseada) para profundizar en el inconsciente colectivo de Carl Gustav Jung, estableciendo un vínculo de doble sentido que conecta lo racional y lo onírico, lo natural y lo urbano. La huida, la represión y la búsqueda de un lugar junto con la construcción de una nueva vida en un nuevo mundo, se convierten en una prioridad tanto vital como artística no sólo para el grupo de París y para Leonora Carrington, sino también para otras artistas en el exilio, entre las que se encontraba la española Remedios Varo, afincada en México a partir del año 1941, quien también destaca por dar uso al Surrealismo como un medio de reivindicación del espacio.
Remedios Varo consigue trazar a lo largo de su obra, de manera inigualable y con un estilo y una iconografía totalmente personales, una línea entre lo natural y lo urbano, otorgándole un significado muy especial a los elementos arquitectónicos y a la ciudad en sí. ${ }^{14}$ Fue capaz de volver la técnica surrealista, en un ejercicio crítico, contra ella mis$m a{ }^{15}$ pues si bien el proceso de realización de sus pinturas estaba vinculado con el azar y la libertad creativa, estos sólo aparecían en sus lienzos para ser controlados. El arte de Varo coincide con el ideal surrealista de expresión del mundo interior, de lo onírico, de lo fantástico y de lo infantil que radica en el interior de todo ser humano. No obstante, su técnica perfeccionista y detallada se opone al automatismo bretoniano, de modo que, más que crear desde el subconsciente, Varo se eleva hacia lo que Susanne Klengel llama "estado de supra-consciencia". ${ }^{16}$

El círculo surrealista de París, al que llegó en 1937 junto con el poeta francés Benjamin Péret, jugó un rol fundamental en su desarrollo como pintora, pues cuando estaba buscando una nueva orientación para todo lo que había adquirido en su formación en la Academia de San Fernando, el Surrealismo sirvió como puerta de entrada a todo lo imaginativo, a la búsqueda en los símbolos, a la experimentación y a la ironía. ${ }^{17}$ No obstante, la joven Remedios asistía a aquellas reuniones entre bambalinas, sin terminar de intervenir del todo, desde la posición tímida y humilde del oyente. ${ }^{18}$

...yo estaba con la boca abierta dentro de ese grupo de personas brillantes y dotadas. Estuve junto a ellos porque sentía cierta afinidad. Hoy no pertenezco a ningún grupo; pinto lo que se me ocurre y se acabó. ${ }^{19}$

La idea de no pertenecer a ningún grupo hace de Remedios Varo una artista empeñada en la construcción de su propio "otro mundo", donde los

12 BACHELARD, Gaston. La poética del espacio. Madrid: Fondo de Cultura Económica, 1965.

13 MOORE, Charlotte. "Surrealism, Religion and Psychology", en LEEMING, David A. (ed.). Encyclopedia of Psychology and Religion. Londres, Springer, 2014, pp. 1758-1760.

14 VIVES, Anna F. "Surrealismo, género y ciudad en la obra pictórica y poética de Remedios Varo", en Ángulo Recto. Revista de estudios sobre la ciudad como espacio plural, vol. 5, 1, 2013, pp. 179-195.

15 KAPLAN, Janet. "Encantamientos domésticos", en GRUEN, Walter \& OVALLE, Ricardo. Remedios Varo. Catálogo razonado. México, Ediciones Era, 1998, pp. 31-40, p. 36.

16 KLENGEL, Susanne. "Bordando el manto terrestre. Remedios Varo y el mundo literario de Thomas Pynchon" en VV.AA. Remedios Varo. Arte y Literatura. Teruel, Museo de Teruel, 1991, pp. 23-31, p. 25.

17 KAPLAN, Janet. Viajes inesperados. El arte y la vida de Remedios Varo. México, Ediciones Era, 1998, p. 69.

18 Remedios Varo en TIBOL, Raquel. Diversidades en el arte del siglo XX. Para recordar lo recordado. México, Universidad autónoma de Sinaloa, 2001, p. 127.

19 Ibidem. 
preceptos del Surrealismo sólo estaban presentes como un sentimiento inherente al ser humano. ${ }^{20}$

Poco se conoce, no obstante, de lo que estaba ocurriendo en este sentido en el contexto europeo y, de manera más precisa, en el corazón del III Reich. Si la I Guerra Mundial se entiende a día de hoy como un suceso que espoleó el camino de las Vanguardias hacia la abstracción, en el que los artistas se convirtieron en aliados del caos, de lo absurdo, el azar y la casualidad, ${ }^{21}$ la II Guerra Mundial actúa dentro de este imaginario a modo de vórtice que absorbe hasta la total invisibilidad todo brote de arte contestatario o situado fuera de los márgenes de los regímenes totalitarios involucrados en la contienda. No obstante, entre las sombras se movían algunas personalidades que ahora comienzan a salir a la luz, como es el caso de la artista austriaca Emmy Haesele. Haesele no gozó de una formación artística como tal, si bien su educación desde pequeña estuvo siempre enfocada al contexto de lo artístico, de la música, de la literatura y de la filosofía.

Desde su juventud se la consideraba en su entorno familiar como una excéntrica, pues no sólo gustaba de realizar actividades normalmente relacionadas con el mundo de los hombres, como escalar o circular en motocicleta a gran velocidad por las calles de Viena junto con su hermana, así como lucir el cabello corto acompañado de un carácter siempre dispuesto a aceptar cualquier prueba de coraje. Su relación con la filosofía se estrecha entre los años 1911 y 1912, cuando fue interna en un Pensionado en Weimar, a los 16 años. El camino hacia el que la conducen sus lecturas traza una línea paralela con el pesimismo histórico que empapa los inicios del Expresionismo alemán. Sus elucubraciones sobre la figura de Dios como creador (extrapolado también al contexto de la creación artística) junto con sus divagaciones sobre su propia identidad la hacen tomar el rumbo que apunta hacia la disolución del Todo en la Nada, una Nada que, por otra parte, puede funcionar como sinónimo de "Origen", pues está llena de referencias a la infancia, a un contexto que guarda muchas similitudes con el inconsciente colecti- vo jungiano. Para Haesele su infancia está fuertemente marcada por el paisaje y las descripciones del pueblo austriaco de Pörtschach am Wörthersee, $^{22}$ aunque en sus diarios, cuando habla de estos paisajes de la infancia hace aún una mayor alusión a la existencia de una "patria interna", un mundo regido por los caprichos del sueño. Será este aspecto, perenne a lo largo de toda su obra, el que la ponga en relación, sin ser ella consciente, con el movimiento surrealista.

La figura de Carl Gustav Jung supone para Haesele (antes Emmy Göhring) no sólo el puente que la une ideológicamente con los artistas del ya mencionado "Surrealismo tardío", sino que también es quien la anima a zambullirse en el mundo del dibujo y de la pintura. Tras su matrimonio con el médico Hans Haesele, la pareja se dedicó a recopilar en su casa de Salzburgo obras sobre teosofía (en concreto se interesan por la obra de Helene von Blavatsky), de psicología cultural y de filosofía histórica. Se insertan en el círculo del "Sazlburguer Museum" y comienzan a asistir a las "Soirées" del escritor Oskar H. Schmitz, quien le sirvió de puerta de acceso a las vanguardias artísticas y literarias procedentes de Francia, así como de vínculo con Carl Gustav Jung, Hans Prinzhorn, Max Scheler y un largo etcétera.

Curiosa, preguntó la Señora Haesele, qué le había recomendado Jung como terapia. "¡Dibujar!", dijo Schmitz. "¿Y, qué pasa entonces, si uno no sabe dibujar?" "Eso da igual. Sólo debe hacerse, independientemente de lo que salga". Schmitz le enseñó a Haesele algunas láminas de esta manera producidas. La impresión que le causaron a la joven fue la de "¡Yo también puedo hacer eso!". ${ }^{23}$

Si bien este círculo no puede considerarse estrictamente surrealista, las actividades que llevaban a cabo en sus reuniones guardaban un estrecho paralelismo con el automatismo literario, con el ensalzamiento de la locura y la interpretación de los sueños como motores artísticos, así como con las ideas de "predestinación" e "indiferencia creativa", del trabajo del filósofo y esotérico Salomo Friendlander. La actividad artística de Haesele estaba marcada por una fuerte tendencia a desactivar

\footnotetext{
20 VARO, Remedios. Cartas, Sueños y otros textos. México, Ediciones Era, 1999, p. 67.

21 USEDA MIRANDA, Evelyn (ed.). Surrealismo. Vasos comunicantes. México, Museo Nacional de Arte, Ediciones el Viso, 2012, p. 15.

22 WALLY, Barbara. Emmy Haesele. Salzburgo, Galerie Altnöder, 1993, p. 8.

${ }^{23}$ Cita de una entrevista de M. Bruckner a Emmy Haesele en 1977, en WALLY, Barbara, 1993, p. 14 (traducción propia al casteIlano). Texto original: Neugirig fragte Frau Haesele, was Jung als Therapie verordnet häte. 'Zeichnen!' sagte Schmitz. 'Was aber dann, wenn man nich zeichnen kann?' 'Das ist egal. Man muß es eben nur tun, egal was dabei herauskomm'. Schmitz zeigte Frau Haesele einige seiner auf diese Weise entstandenen Blätter. Was die junge Frau zu der Bemerkung veranlaßte: Das kann ich auch!'
} 
el control racional a la hora de crear, igual que ocurre con la escritura automática de André Breton. No obstante, su camino hacia la construcción de otros mundos, hacia la demanda de nuevos espacios dominados por la presencia de lo femenino, va de la mano, como ocurre en el caso de Leonora Carrington y de Remedios Varo, de la fatalidad, de la represión y de una trágica historia de amor.

Los años que enmarcan el auge del nazismo en Alemania y en Austria, así como los años de la contienda, suponen para Emmy Haesele la pérdida de aquello en torno a lo que había construido su vida. Entre 1933 y 1936 mantuvo una relación amorosa y clandestina con el cuñado de Oskar $\mathrm{H}$. Schmitz, el artista Alfred Kubin. Si bien Emmy Haesele ya había comenzado a realizar obras que definían su estilo personal, estos tres años están marcados por una inactividad pictórica, aunque continuó escribiendo reflexiones estéticas en sus diarios confeccionadas a raíz de sus conversaciones con Kubin, donde desplegaba todo un imaginario vinculado estrechamente con algunos símbolos de las Vanguardias que ya se venían viendo en el contexto francés: el arlequín, el bufón y el teatro del mundo comienzan a ganar fuerza en la confección del mundo imaginario de la joven artista. No obstante, el idilio no tardó en desvanecerse. A pesar del duro golpe que supuso el cese de las visitas al hogar de Kubin, las cartas siguieron fluyendo, no obstante, enfocadas cada vez más a los acontecimientos políticos.

El discurso de Hitler en Salzburgo, en el año 1938, sedujo al hijo de Emmy y Hans Haesele hasta conducirlo a la muerte en la frontera con Francia poco tiempo después. La muerte del hijo, el encarcelamiento por la Gestapo de su hija y el marido de esta (quien sería poco después asesinado) y la posterior muerte de Hans, perdido en los Balcanes en otra campaña militar, hicieron que Emmy Haesele se predispusiera a alistarse como voluntaria en el cuerpo de artillería antiaérea en Münster, buscando precisamente el mismo destino de su marido y su hijo: la muerte.

No obstante, pudo volver a Salzburgo junto con su hija, donde serían encarceladas por la denuncia de los soldados americanos que habían ocupado la ciudad. Los meses de encarcelamiento transcurrieron para Haesele con una impetuosa necesidad de escribir sobre los horrores que allí se veían.
Finalmente, su hermana consiguió liberarlas y se establecieron juntas en Bad Aussee, donde se produce el estallido de la obra pictórica de Haesele y de donde proceden sus obras más interesantes, seguidas de una conversión al catolicismo que marca su posterior etapa vienesa, transcurrida en compañía de Ernst Fuchs, Arnulf Rainer y su círculo de artistas en el Café Hawelka.

Durante su estancia en Bad Aussee, que transcurre entre 1948 y 1956, comienza a crear imágenes de "lugar sin lugar", u "Ortlos", como ella las llama. Son siempre espacios imaginarios con un trazado urbano imposible donde reverberan las imágenes de la ciudad de su infancia y donde se abren puertas y ventanas en torres y logias que se dirigen hacia otros mundos, a otras ideas, a otros símbolos. Esta composición casa con la idea de Michel Foucault de "heterotopía", que se define como un espacio en el que estamos inmersos, bien sea real o ilusorio. Se trata de espacios liminares, percibidos de una manera muy similar a como percibimos nuestro reflejo en el espejo, pues pertenece doblemente a la realidad y al mundo inexistente de las posibilidades, donde estamos ausentes pero a la vez podemos confirmar el espacio que ocupamos. ${ }^{24}$ Así pues, aparecen plasmados sobre el papel espacios de frontera, de límites entre un mundo y otro, entre lo natural y lo urbano, entre la vigilia y el sueño, etc.; ideas que, de manera coetánea y extraordinariamente sin haber mantenido ningún tipo de contacto, aparecen en la obra de Remedios Varo en México, cuyas ciudades también evocan el paisaje de la infancia: la medieval Anglès, donde residió solamente hasta 1916.

La experiencia del paisaje implica asimismo la aceptación de una multiplicidad de significados dentro de la misma estructura urbana o natural. La ciudad puede ser varios lugares y puede originar múltiples puntos de vista y acercamientos. El papel del artista situacionista casa muy bien con la creación artística de Varo y Haesele en el sentido de que ellas mismas construyen sus ciudades a partir de experiencias previas del paisaje, originando lo que Esteban-Guitart denomina "paisajes psicológicos", ${ }^{25}$ donde prima la idea de construir un espacio protector y femenino que a su vez compele una experiencia de transcendencia.

Aunque la presencia del entramado urbano no es tan evidente en la obra de Varo como en la de

24 FOUCAULT, Michel. "Des espaces autres" en DEFERT, Daniel \& EWALD, François (ed.). Dits et écrits 1954-1988. París, Gallimard, 1994, pp. 752-762, pp. 755-756.

25 ESTEBAN-GUITART, Moisés. "La psicogeografía cultural del desarrollo humano", en Boletín de la Asociación de Geógrafos Españoles, n59, 2012, pp. 105-128. 
Haesele, sus pinturas y sus poemas siempre incluyen ciudades procedentes de otros tiempos, aunque no con la idea de pasado sino con una atemporalidad que le es propia al mundo de los sueños. Las ciudades de Remedios Varo se distancian de las ciudades surrealistas, como la que puede apreciarse en Nadja. Las ciudades surrealistas podían entenderse de la misma manera en la que se entendían los objetos: representaciones sensibles provocadas por acciones inconscientes que no consisten en otra cosa más que en una "encarnación de los anhelos", en una transmutación poética de las cosas que nos rodean, que dependen principalmente de la imaginación amorosa de cada uno. ${ }^{26}$ Este aspecto hace adoptar tanto al objeto como a la ciudad una actitud totalmente pasiva, algo que debía ser descubierto, algo que se vistió con los ropajes femeninos. En la obra de Varo sus espacios pueden entenderse, por el contrario, como sujetos activos que guardan una relación orgánica con los personajes que los pueblan, con la idea del "otro".27 Así pues, las barreras entre el objeto y el sujeto desaparecen, ya bien sea dentro del cuadro o dentro de la relación entre obra y espectador.

Lo mismo ocurre con la obra de Haesele. Las ciudades muchas veces aparecen en forma antropomórfica como en Marchenerzählerin ${ }^{28}$ (1975), que miran directamente al espectador o que le interpelan a partir de los personajes que se asoman a sus puertas y ventanas, por ejemplo, en Der blaue Himmel über Uns ${ }^{29}$ (1962) (fig. 1). Aquí un ser fantástico nos sostiene la mirada mientras que desde las ventanas de la casa sobre la que reposa se muestran diferentes imágenes que nos hablan del paso del tiempo, de la vida y la muerte, cosa que también puede apreciarse en las composiciones de Remedios Varo. En las obras de Haesele siempre hay un centro claro, con mucha fuerza, marcado casi en la totalidad de sus obras por un animal de proporciones descomunales o por la figura del Arlequín, de la Mujer o, más adelante, de la Virgen María. La presencia de los cuatro elementos, en una lectura casi alquímica que bien puede ponerse en relación con la obra de Varo, conforma los espacios de la ciudad o sirve para señalar su destino, un destino que llama a la disolución y a la Nada. Este movimiento centrífugo o la idea de disolución de los espacios tam-

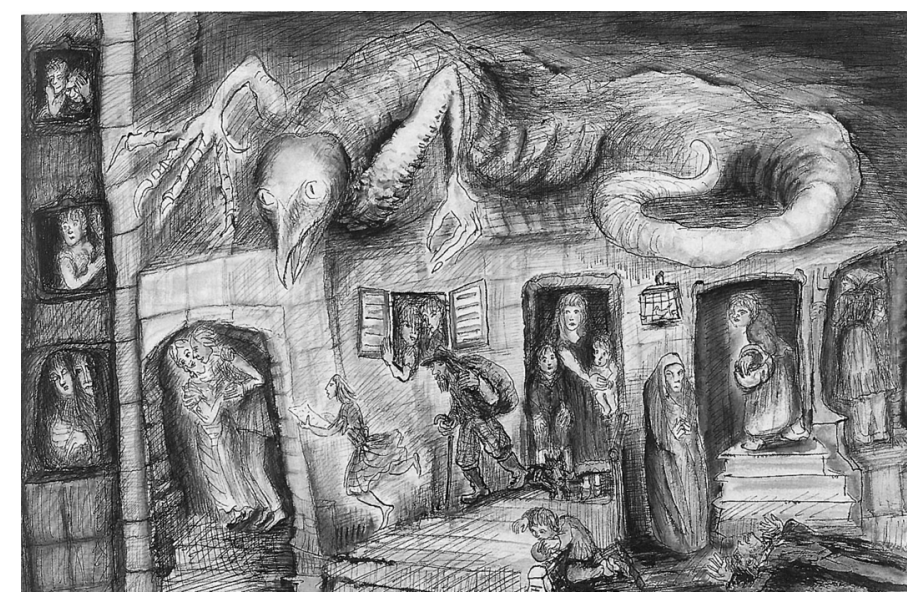

Fig. 1. Emmy Haesele. "Der Blaue Himmel über Uns" [El cielo azul sobre nosotros], 1962. Tinta china/Acuarela. (c) Galerie Altnöder Salzburg.

bién puede apreciarse en algunas obras de Varo, donde los objetos salen, literalmente, de los límites de lo arquitectónico y se funden con sus propios personajes, como ocurre en la obra Hacia la Torre (1960) o Bordando el manto terrestre (1961) (fig. 2).

Aunque las imágenes y las composiciones son similares, el sentido de las ciudades en la obra de Varo y Haesele toman caminos divergentes que pueden relacionarse con sus experiencias vitales y con su doble condición de mujeres y perseguidas (cada una en su contexto), abordado esto siempre desde una perspectiva crítica.

La imagen de la ciudad en Remedios Varo puede hacernos pensar, mayoritariamente, en una fuerza que va "hacia afuera", centrífuga. Sus composiciones muestran unos personajes y unos límites espaciales que invitan al observador a "salir de la ciudad". Esta idea de abandonar la ciudad para distanciarse del mundo de la lógica y sumirse en el imaginario aparece también en algunos de sus escritos, destacando quizás Días de Meditación:

Felina y Ellen están instaladas desde hace dos días en una tienda de campaña que trajeron consigo cuando decidieron alejarse por algún tiempo de la ciudad,

\footnotetext{
26 CIRLOT, Juan Eduardo, 1986, p. 90.

27 VIVES, Anna. 2013. p. 184.

28 Traducción: Cuentacuentos.

29 Traducción: El cielo azul sobre nosotros.
} 


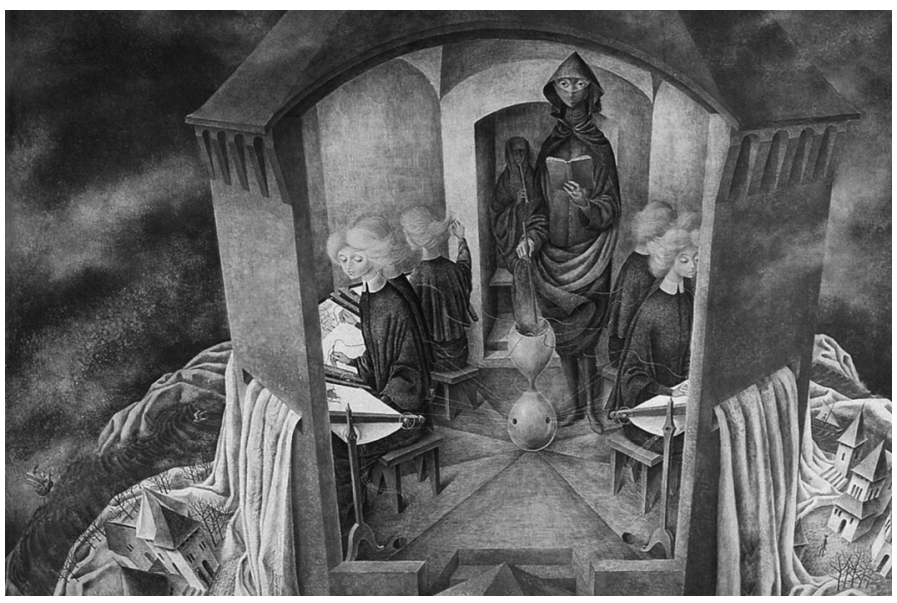

Fig. 2. Remedios Varo. "Bordado del Manto Terrestre", 1961. Óleo/Masonite. (C) Derechos Reservados, 2015. Remedios Varo.

pues tanto la una como la otra necesitaban descanso y unos días de meditación para poner orden en el tumulto de sus temores, emociones y dudas. ${ }^{30}$

Remedios Varo nos presenta una opción de huida, una solución a la desolación. ${ }^{31}$ En sus pinturas persiste la idea de destino y de tiempo en el espacio compositivo, pero sin llegar a mostrar la destrucción, más bien al contrario. Esta idea de tiempo instaura un orden cósmico donde la figura de la mujer es crucial para su consecución. ${ }^{32}$

No obstante, la sensación de incomodidad, en el sentido freudiano de unheimlich, impregna las ciudades de Varo. En otro de sus textos, Verdad Absoluta, se presenta la ciudad amurallada a modo de patíbulo, de cerco y de telón de fondo para abordar uno de los temas más tratados por la artista en sus pinturas: el hilo del destino y la conexión de todos los individuos en un gran tapiz, un tapiz que, en relación con la idea de la confección de un nuevo cosmos, aparece tejido por mujeres. Junto con Bordado del manto terrestre (1961), otra de las obras que mejor ilustra esta idea es Tres Destinos (1956) (fig. 3), donde en el plano de una ciu- dad tan medieval como atemporal se abren tres grandes vanos desde los que se ve a tres personajes unidos tanto por la actividad creativa que desempeñan como por los hilos que emergen de un gran huso en el centro de la composición.

La idea de contraste entre vida (entendida a modo de creación, de amor) y muerte perfila una ciudad que se define como un espacio que permite la comunicación entre los contrarios, ${ }^{33}$ del mismo modo que reivindica su papel en la confección de la "heterotopía" que supone el gran espectáculo de la ciudad. ${ }^{34}$ Aun así, el sentido que permanece siempre tras estas representaciones no es trágico, sino que refleja un mundo de paz, de equilibrio, donde lo imaginario se torna maravilloso. Como dice Fernando Martín Martín, en el universo de Remedios Varo no hay lugar para el horror, la angustia o la agresividad, sino que sus historias son armoniosas, serenas, de carácter mágico. ${ }^{35}$

El verdugo me llevó a un lugar que parecía como la muralla de una ciudad; de cada lado de la muralla bajaba una pendiente muy inclinada de tierra. (...) "¿Por qué tienes miedo a la muerte si sabes tanto? Teniendo en cuenta tu sabiduría no debías temer a la muerte". Entonces me di cuenta, de repente, que lo que él decía era cierto y que mi horror era no tanto hacia la muerte, sino por haber olvidado hacer algo de suma importancia antes de morir. (...) Le expliqué que yo amaba a alguien y que necesitaba tejer sus "destinos" con los míos, pues una vez hecho este tejimiento quedaríamos unidos para la eternidad. ${ }^{36}$

La ciudad de Haesele, no obstante, está más vinculada con el sentido carcelario. La introspección que realiza la autora en el contexto urbano de sus dibujos está dirigida hacia la imagen del espacio uterino, y todo aquello que salga de ese espacio está destinado a morir, está destinado a disolverse en la Nada. Esta percepción del espacio y del paisaje urbano está directamente vinculada con sus experiencias durante la II Guerra Mundial, encontrando ejemplos autobiográficos en Im Luftschutz-

30 VARO, Remedios. "Días de Meditación", en MENDOZA BOLIO, Edith. A veces escribo como si trazase un boceto. Los escritos de Remedios Varo. Madrid, Iberoamericana, 2010, pp. 216-222, p. 216.

31 VIVES, Anna F., 2013. p. 193.

32 Ibidem.

33 Ibidem.

${ }^{34}$ DE DIEGO, Estrella. Remedios Varo. Madrid, Fundación Mapfre, Instituto de Cultura, 2007, p. 67.

${ }^{35}$ MARTín MARTíN, Fernando. "Notas a una exposición obligada: Remedios Varo o el prodigio revelado", en Laboratorio de Arte, $n^{\circ} 1,1988$, pp. 231-246, p. 233.

36 VARO, Remedios. "Verdad Absoluta", en MENDOZA BOLIO, Edith. 2010, p. 210. 
keller ${ }^{37}$ (1946) (fig. 4), donde imagina el sótano de la batería antiaérea de Münster como una muralla medieval con cabeza de mujer doliente. Dentro de esta muralla aparece una cavidad donde se refugian mujeres y niñas, volviendo de nuevo a la imagen uterina. La idea de salir del útero para morir puede apreciarse en Dem Krieg gebären ${ }^{38}$ (1948), donde una representación femenina de proporciones monumentales que simboliza la madre tierra da a luz a sus hijos, que se convierten en soldados y se dirigen, dando la espalda al espectador, hacia una ciudad en ruinas, ribeteada por una franja color bermellón que alegoriza la batalla.

Por tanto, si la fuerza del paisaje en Remedios Varo representaba un movimiento "hacia afuera", en Emmy Haesele sus ciudades están dominadas por una fuerza centrípeta, "hacia adentro":

Cuando me aproximo al sentido de mis imágenes, me llama la atención, que una gran parte de las mismas muestran la figura de un útero, y que también el contenido de las imágenes se encamina siempre hacia el mismo tema: nacimiento, desarrollo, anhelo de salvación del enredo terrenal y de la extinción en lo vegetativo y lo demoníaco. (...) No es por tanto de la luz del mundo de lo que mi humana conciencia se empapa primero, sino de un "nacer hacia adentro" en una oscura, estrecha y sangrienta prisión. (...) "Déjanos hacer [oh, Dios] a nosotros los hombres, una imagen que nos sea par..." Él se reflejará en nosotros - isantificada sea tu voluntad! Nuestra tarea es la de realizar esta voluntad, primero volviendo a nuestro lugar de origen. ${ }^{39}$

La profunda conversión al cristianismo de Emmy Haesele en su retiro de Bad Aussee hizo que sus figuras fueran cambiando paulatinamente de significado, tornando a un contenido espiritual. La figura del Arlequín pasa a convertirse en una representación de Cristo, así como las figuras femeninas que antaño dominaban sus dibujos, van sustituyéndose por ángeles o imágenes marianas. No obstante, no termina de abandonar su formación en teosofía y hermetismo. Así pues, la figura del Arlequín pasa a dividirse en dos personalidades: el "Eulenspiegel", que adquiere un rol muy similar a la figura del Joker, y el "Narr" o bufón. Ambos re-

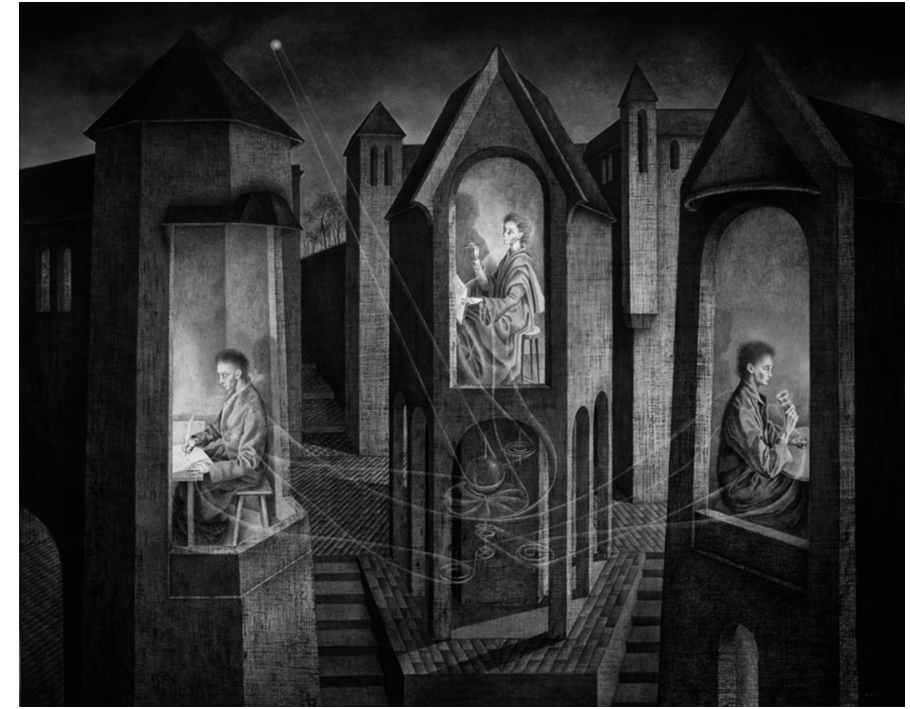

Fig. 3. Remedios Varo. "Tres Destinos”, 1956. Óleo/Masonite. (C) Derechos Reservados, 2015. Remedios Varo.

presentan por separado un tipo diferente de conocimiento trascendente, y sólo cuando se unen surge un sentido completo de trascendencia. Esto puede recordar también a la utilización de figuras andróginas en la obra de Remedios Varo, cuya formación también estrecha lazos con la alquimia. Los personajes del "Narr" y el "Eulenspiegel" aparecen siempre en el telón de fondo de un teatro, de una ciudad como teatro de la humanidad. Aquí predomina la idea de juego, de experimentación. El propio "Eulenspiegel", como su nombre sugiere (traducido literalmente como "Búho-Espejo"), se muestra portando un espejo, lo cual también nos lleva directamente hacia el concepto de "heterotopía" en la obra de Varo. Todo es un juego, todo es un reflejo, y en ese reflejo la ciudad que se nos muestra responde a la imagen romántica de las ruinas. Estas ruinas, ciudades vivas que desaparecen, son comparadas por Barbara Wally con la ciudad de Praga que se presenta en El Golem de Gustav Meyrink y de Murnau.

\footnotetext{
37 Traducción: En el sótano de la batería antiaérea.

38 Traducción: Parir la guerra.

39 Diario de Emmy Haesele, entrada del 11 de diciembre de 1950, recogido en WALLY, Barbara. 1993. pp.37-38. Traducción propia. Original: Wenn ich so die Fülle meiner Bilder betrachte, so fällt mir auf, daß ein großer Teil derselben formal die Gestalt eines Uterus aufweist, und auch der innere Gehalt der Bilder wandelt immer wieder das eine Thema ab: Geburt - Wiederung - Sehnsucht nach Erlösung aus den irdischen Verstrickungen und ein Herausstreben aus dem Vegetativen und Dämonischen. (...) Es ist also nicht das Licht der Welt, das sich meinem menschlichen Bewußtsein zuerst einprägte, sondern das Hineingeborenwerden in ein dunkles, enges, blutliges Gefängnis. (...), Lasset Uns Menschen machen, ein Bild das Uns gleich sei...' Er will sich in uns spiegeln - geheiligt Dein Wille! Unsere schwere Aufgabe ist es, diesen Willen zu erfüllen, erst dann kehren wir in die Heimat zurück.
} 


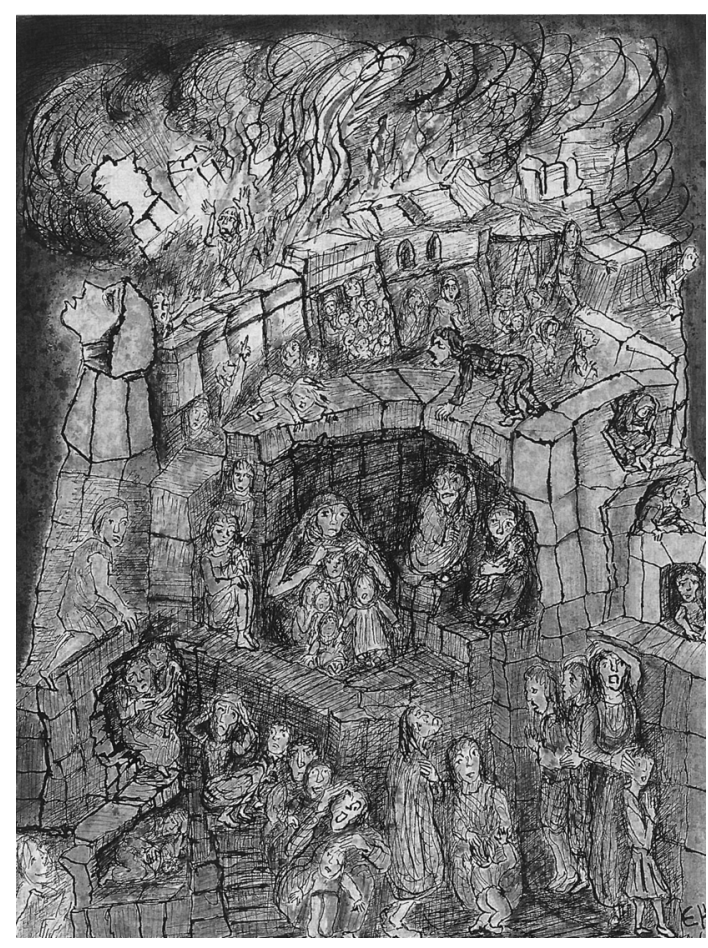

Fig. 4. Emmy Haesele. "In Luftschutzkeller" [En el sótano de la batería antiaérea], 1946. Tinta china/Acuarela. (C) Galerie Altnöder Salzburg.

Creo que todas estas ruinas son símbolos visibles de la quiebra total de una época cultural. No obstante, también tengo la sensación de no ser más una "Sepulturera", sino más bien una "Enterradora de tesoros" -que a partir del trabajo de remover los escombros, libera fuentes escondidas. ${ }^{40}$

En este juego de reflejos, de fuerzas contrarias que colisionan y se unen, emerge la idea de la espiral. La espiral se alza como símbolo que une la trayectoria artística de ambas pintoras, aún sin haber llegado a conocerse nunca. Conecta, además, ambos planteamientos y ambas aproximaciones a la ciudad con un sustrato mucho más profundo y remoto en el tiempo, y es que desde Platón en su definición de la ciudad ideal de la Atlántida, ya se nos muestra un plano de círculos concéntricos que se expanden hacia afuera al mismo tiempo que nos llevan hacia el corazón de la ciudad. Luquín Calvo compara el plano circular de la ciudad ideal clásica con la espiral en un sentido de trascendencia que acoge tanto la obra de Emmy Haesele como la de Remedios Varo.

En el círculo no hay lugar para que los bienaventurados abran sus alas, ellos que son como pájaros impensables. Tampoco puede haber lugar para otros universos, otros pájaros, otras almas hijas del creador, además de las que ya conocemos. ${ }^{41}$

En la espiral, por tanto, se abre la idea de penetrar en otros mundos. Las ciudades, tanto en el caso de Varo, como en el de Haesele, funcionan como palimpsestos. Pese a las realidades políticas que configuran el funcionamiento de las ciudades, no puede obviarse en primera instancia la relación de estas con la naturaleza, con lo mítico y lo imaginario. Esta relación de la ciudad de la Modernidad con los mitos antiguos rompe la idea de la existencia de un tiempo progresivo en pos de un eje temporal que, a la par que avanza, gira sobre sí mismo: de nuevo la imagen de la espiral. ${ }^{42}$

En este sentido destacan las obras Tránsito en espiral (1962) (fig. 5) de Remedios Varo, y Maria mit Kind inmitten einer sündigen Stadt ${ }^{43}$ (1958) (fig. 6) de Emmy Haesele. En ambos casos aparece la imagen de una ciudad dispuesta en espiral sobre un centro. Se abre ante los ojos del espectador un espacio rizomático donde las imágenes, procedentes del sustrato de lo imaginario, se mueven en ambas direcciones de la espiral, representando así el espíritu colectivo, la conciencia de las personas en su peregrinación constante en busca de una meta que, aún sin saberlo, se corresponde con el lugar de origen, con el centro de la composición.

Esta imagen, tremendamente romántica, puede resumirse perfectamente en las palabras de Meyer Howard Abrams, para quien:

...la redención, incluso después de ser trasladada a la
historia y traducida en la autoeducación del espíritu
general de la humanidad, sigue representándose
con el tropo cristiano central de la vida como pere-
grinación y búsqueda: la "Bildungsgeschichte" de la
filosofía romántica de la conciencia tiende a imagi-

40 HAESELE, Emmy. "Nachlass", en WALLY, Barbara, 1993, p. 48. Traducción propia. Original: Ich glaube, daß alle diese Ruinen sichtbare Symbole sind für den ganzen Zusammenbruch einer Kulturepoche. Trotzdem habe ich ja nicht eben das Gefühl ,Totegräber' zu sein, sondern weit eher ,Schatzgräber' -daß gerade durch die Arbeit des Schuttabtragens die verborgenen Quellen wieder freigelegt werden.

${ }^{41}$ LUQUÍN CALVO, Andrea. 2008, p. 189.

42 LEHAN, Richard. The City in Literature: an intellectual and cultural history. Berkeley, University of California Press, 1998, pp. $22-23$.

43 Traducción: María con el Niño en medio de la ciudad pecadora. 
narse en la forma narrativa de un "Bildungreise" cuyo fin es su propio comienzo. ${ }^{44}$

La confección de la ciudad como fondo para las pinturas de Remedios Varo y Emmy Haesele se muestra, por tanto, como un espejo de su propia existencia, levantado por la mano del "Eulenspiegel", o como el hermafrodita que se multiplica en los confines del entendimiento, dando muestra de la diversidad de la imaginación que brota de un sustrato común.

Para concluir me gustaría utilizar las palabras que Eduardo Cirlot escribe a la hora de referirse a la concepción del mundo en el arte surrealista, que respondía a un:

...sistema de cosas que se encuentran entre los dos polos de la aniquilación: el que niega toda objetividad por creer que el universo es una inmensa mascarada en la que una sola presencia se goza en escisiones y disfraces, y el que abandona cada aparición del ser en el pozo de su propia entidad, sin concederle otro valor que el utilitario (al fin también fantasmagórico). ${ }^{45}$

A una parte de este mundo surrealista pertenece el arte de Remedios Varo, plagado de alusiones a la máscara, al juego, donde sólo el ser, la figura principal, a veces solitaria, de sus composiciones aglutina toda la importancia y la significación de "ser"; mientras que el mundo que se diluye hacia las profundidades de sí mismo y hacia los dominios del inconsciente colectivo, nos lleva directamente a la obra de Emmy Haesele. Tanto en la una como en la otra, el "valor surrealista" de su arte se encuentra en la finalidad del mismo: profundizar y buscar en el individuo. ${ }^{46}$ La producción artística de ambas cuestiona la idea del espacio como algo escindido del todo y del ser humano, y en condición de mujeres en una época donde no gozaban de tantas libertades como podían imaginar, prevalece la idea de unión entre cuerpo físico y espacio trascendente, que toma un tinte aún más relevante.

En líneas generales, tanto Emmy Haesele como Remedios Varo fueron dos artistas influenciadas por el Surrealismo francés, que más que buscar un nuevo arte, buscaba un hombre nuevo en el que primara el ascenso a lo maravilloso, el descenso a lo insondable y la representación de las experiencias que este tránsito conlleva. ${ }^{47}$ Este via-

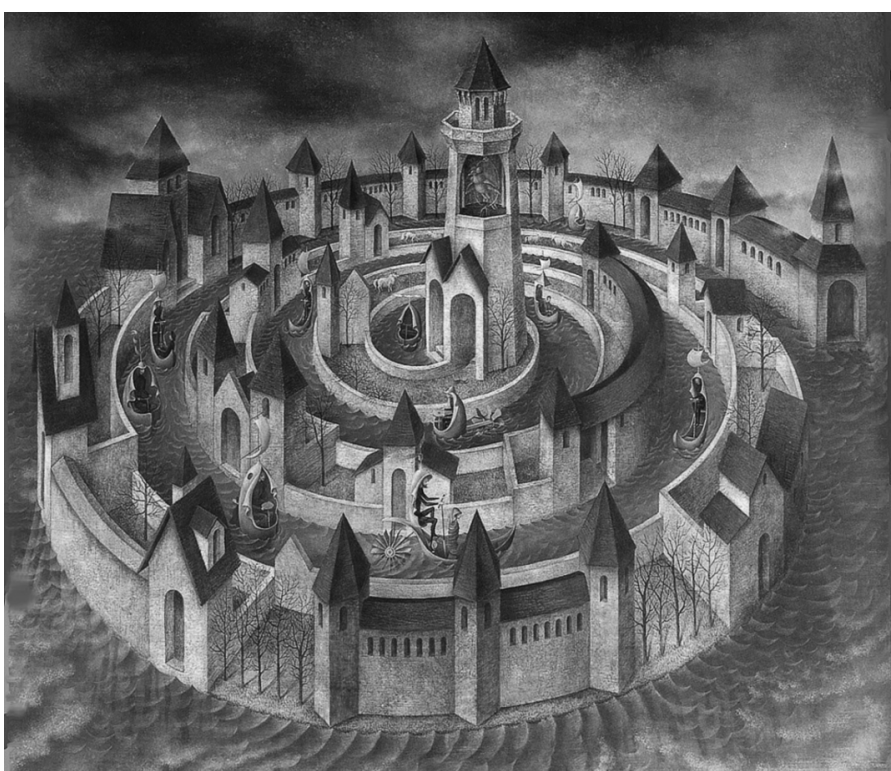

Fig. 5. Remedios Varo. “Tránsito en espiral”, 1962. Óleo/Masonite. (C) Derechos Reservados, 2015. Remedios Varo.

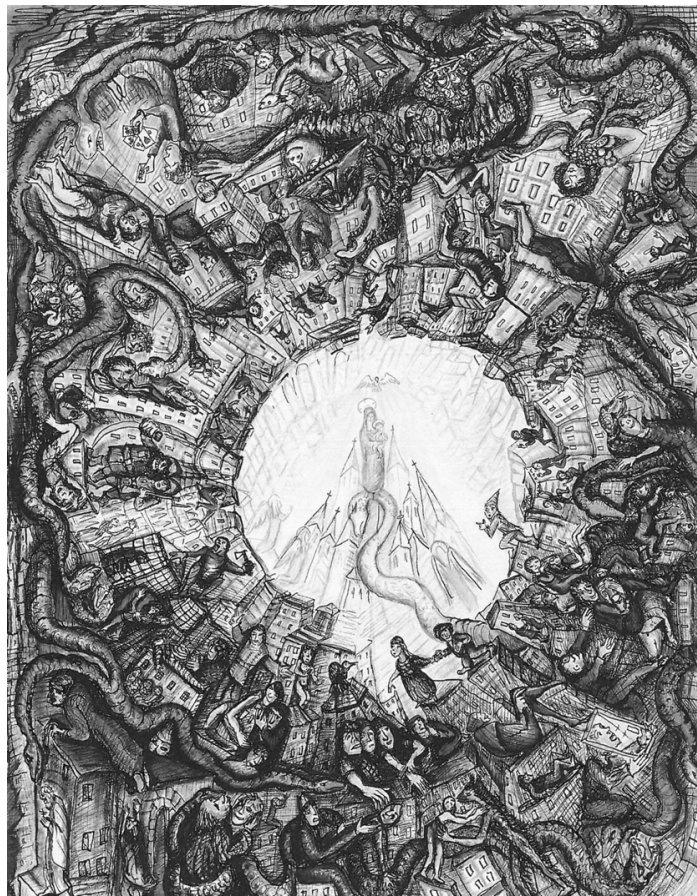

Fig. 6. Emmy Haesele. "Maria mit Kind inmitten einer sündigen Stadt" [María con el Niño enmedio de una ciudad pecadora], 1958. Tinta china/Acuarela. (C) Galerie Altnöder Salzburg.

44 ABRAMS, Meyer Howard. Romanticismo, tradición y revolución. Madrid, Visor, 1992, pp. 184-185.

${ }^{45}$ CIRLOT, Juan Eduardo. 1986, p. 95.

${ }^{46}$ GAUSS, Charles E. "The theoretical Backgrounds of Surrealism", en Journal of Aesthetics and Art Criticism, vol. 2, 8, pp. 37 44, p. 40.

47 MENDOZA BOLIO, Edith. 2010. p. 14. 
je de ida y vuelta se concentra en un eje a partir del cual todas las posibilidades de recorrer los caminos de la expresión artística en relación con el subconsciente se multiplican. En este eje entrelazan sus hilos y sus destinos Remedios Varo y Emmy Haesele, cada una mirando hacia un lado del Atlántico, hacia un contexto histórico diferente. Se dan la espalda la una a la otra: una dirige la mirada hacia arriba, más allá de las estrellas; la otra, hacia lo más profundo de sus abismos. Pero el hilo del Surrealismo entreteje sus destinos, si bien no en la vida real, sí en el imperecedero mundo de la pintura, al amparo de la gran ciudad atemporal que siempre las ha acompañado y ha velado por sus sueños.

\section{Bibliografía}

ABRAMS, Meyer Howard. Romanticismo, tradición y revolución. Madrid: Visor, 1992.

ALTNÖDER, Ferdinand; ALTNÖDER, Heidi. Emmy Haesele. Salzburgo: Galerie Altnöder, 1987.

AROS LEGAND, Pablo. "Cuerpo de mujer: la ciudad como constructo en el discurso poético femenino desde los años ochenta hasta la actualidad en Chile". Ángulo Recto. Estudios sobre la ciudad como espacio plural. 9 (1), 2017, pp. 5-15.

BACHELARD, Gaston. La poética del espacio. Madrid: Fondo de Cultura Económica, 1965.

BARREIRO LEÓN, Bárbara. "Psicogeografía y ciudad: iconografía del urbanismo surrealista" Ángulo Recto. Revista de estudios sobre la ciudad como espacio plural. 7 (1), 2015, pp. 5-12.

CHEVALIER, Jean \& GHEERBRANT, Alain. Diccionario de los Símbolos. Barcelona: Herder, 1991.

CIRLOT, Juan Eduardo. El mundo del objeto a la luz del surrealismo. Barcelona: Athropos. 1986.

DE DIEGO, Estrella. Remedios Varo. Madrid: Fundación Mapfre, Instituto de Cultura, 2007.

ESTEBAN-GUITART, Moisés. "La psicogeografía cultural del desarrollo humano". Boletín de la Asociación de Geógrafos Españoles, n 59, 2012.

FOUCAULT, Michel. "Des espaces autres" en DEFERT, Daniel \& EWALD, François (ed.). Dits et écrits 1954-1988. París: Gallimard, 1994, pp. 752-762.

GAUSS, Charles E. "The theoretical Backgrounds of Surrealism". Journal of Aesthetics and Art Criticism, vol. 2, 8, pp. 37-44.

JUNG, Carl Gustav \& STEPHENSON, Craig E. On Psychological and Visionary Art. Notes from C. G. Jung on Nerval's Aurélia. Princeton: Princeton University Press, 2015.
KAPLAN, Janet. "Encantamientos domésticos" en GRUEN, Walter \& OVALLE, Ricardo. Remedios Varo. Catálogo razonado. México: Ediciones Era, 1998, pp. 31-40.

KAPLAN, Janet. Viajes inesperados. El arte y la vida de Remedios Varo. México: Ediciones Era, 1998.

KLENGEL, Susanne. "Bordando el manto terrestre. Remedios Varo y el mundo literario de Thomas Pynchon" en VV.AA. Remedios Varo. Arte y Literatura. Teruel: Museo de Teruel, 1991, pp. 23-31.

LEHAN, Richard. The City in Literature: an intellectual and cultural history. Berkeley: University of California Press, 1998.

LUQUÍN CALVO, Andrea. Remedios Varo: el espacio y el exilio. San Vicente del Raspeig: Centro de Estudios sobre la Mujer, Universidad de Alicante, 2008.

MAEDING, Linda. "Zwischen Traum und Erwachen: Walter Benjamins Surrealismus-Rezeption". Revista de Filología alemana, 20, 2012, pp. 11-18.

MARTÍN MARTíN, Fernando. "Notas a una exposición obligada: Remedios Varo o el prodigio revelado". Laboratorio de Arte, $n^{\circ} 1$, 1988, pp. 231-246.

MENDOZA BOLIO, Edith. A veces escribo como si trazase un boceto. Los escritos de Remedios Varo. Madrid: Iberoamericana, 2010.

MOORE, Charlotte. "Surrealism, Religion and Psychology" en LEEMING, David A. (ed.). Encyclopedia of Psychology and Religion. Londres: Springer. 2014, pp. 1758-1760.

ONFRAY, Michel. Política del rebelde. Barcelona: Anagrama, 2011.

POULET, Georges. Les méthamorphoses du Cercle. París: Flammarion, 1961.

RAMÍREZ, Juan Antonio. "La ciudad surrealista" en BONET CORREA, Antonio. El Surrealismo. Madrid: Cátedra. 1983, pp. 71-90.

STEINWERDTNER, Brita. Du Engel, du Teufel. Emmy Haesele un Alfred Kubin. Innsbruck y Viena: Haymon Verlag, 2012.

TIBOL, Raquel. Diversidades en el arte del siglo XX. Para recordar lo recordado. México: Universidad autónoma de Sinaloa, 2001.

TRÍAS, Eugenio. El artista y la ciudad. Barcelona: Anagrama, 1983.

USEDA MIRANDA, Evelyn. Surrealismo. Vasos comunicantes. México: Museo Nacional de Arte, Ediciones el Viso, 2012.

VARO, Remedios. Cartas, Sueños y otros textos. México: Ediciones Era, 1999.

VIVES, Anna F. "Surrealismo, género y ciudad en la obra pictórica y poética de Remedios Varo". Ángulo Recto. Revista de estudios sobre la ciudad como espacio plural, vol. 5, 1, 2013, pp. 179-195.

WALLY, Barbara. Emmy Haesele. Salzburgo: Galerie Altnöder, 1993.

ZECHLIN, René. Der Andere Seite - Erzählungen des Umbewussten. Ludwigshafen am Rhein: WilhelmHack-Museum, 2017. 